\title{
Review of Literature on knowledge regarding the risk factors on occurrence of Coronary Artery Diseases among sedentary workers Mr. Nemi Chand Jat ${ }^{1}$ Prof. (Dr.) Yogesh Yadav ${ }^{2}$
}

\author{
${ }^{1}$ Ph.D. Scholar, Maharaj Vinayak Global University, Jaipur, Rajasthan \\ ${ }^{2}$ SUPERVISOR Dean/Principal, Maharaj Vinayak Global University, Jaipur, Rajasthan \\ Corresponding Email:- nemijat60@gmail.com
}

\section{Background of the study:-}

Coronary artery disease should now be considered an important public health problem due to epidemiological transition characterized by changing lifestyles and a problem related to interplay of factors with regards to their existence, causality and attributes. The epidemiological factors like ageing and changing lifestyles, which culminate in an epidemic of non communicable disease is rapidly occurring in the developing countries.

Key Words: Need of the study, Risk factors on occurrence of C.A.D., Coronary Artery Disease

\section{Introduction:-}

Emerging evidence indicates that certain types of sedentary behavior may lead to greater CVD risk than others, which has led some to speculate that "not all sedentary behavior is created equal." Several studies have found that leisure-time sedentary behavior, primarily television (TV) viewing, is more strongly associated with CVD risk factors compared with nonleisure forms of sedentary behavior suggestive that TV viewing may be a more harmful form of sedentary behavior. These previous studies have been limited by their cross-sectional rather than prospective design, and have rarely included diverse populations with high proportions of blacks. Furthermore, although population-based.

Studies have increasingly used accelerometers to objectively measure sedentary behavior to elucidate its role as a CVD risk factor, a limitation of accelerometry-based studies is the difficulty in distinguishing between differing types of sedentary behavior. Epidemiologic evidence from prospective studies, therefore, is still needed to determine if the association of sedentary behavior with incident CVD and mortality varies by leisure versus nonleisure domains.

The WHO expert committee on prevention of Coronary Artery Disease identified a number of lifestyles and environmental factors as the underlying 
causes of CHD. These risk factors may be conceptualised as modifiable and non modifiable. Age, sex, smoking history of high blood pressure, diabetes, elevated plasma cholesterol /triglycerides, obesity, sedentary lifestyle, personality type and psychological stress are considered some of the major risk factors for CAD. Of the many known risk factors, age, sex and genetic pre - disposition cannot be altered. Other risk factors can be altered and therefore, it is essential to characterize specific risk factors that influence the rapid progress of this disease in various ethnic populations.

A literature review may be conducted as itself or as part of a research study. Review of literature is a key step in research process. Review of literature refers to an extensive, exhaustive and systematic examination of publications relevant to the research project. The review of literature in a research report is a summary of current knowledge about a particular practice problem and includes what is known and not known about the problem.

"A literature review is a compilation of resources that provides the ground work for further study". ${ }^{15}$ [Laura A. Talbot, 1995].

Review of literature is the systematic and critical review of the most important published scholarly on a particular topic. This helps the investigator to find what $\mathrm{s}$ already known and what problems remain to be solved. Since effective research is based upon past knowledge, this exercise provides useful hypothesis and helpful suggestions for significant investigation.

Literature Review is presented in following heading.

1. Literature Review related to Knowledge on risk factors of coronary artery diseases.

2. Literature Review related to The Risk Factors On Occurrence Of Coronary Artery Disease

3. Literature Review related to Effectiveness of structure teaching programme.

\section{Literature Review related to Knowledge on Risk factors of coronary artery diseases}

A cross-sectional study of 2650 male and 751 female employees of the IBM company was conducted to compare the risk profiles for CHD between men and women and to analyse the awareness of risk status of people at risk. Analysis showed that women had lower levels of cardiovascular risk factors compared to men. Of the people with hypertension only $22 \%$ of the men and $19 \%$ of the women were aware of their 
hypertension and only $2 \%$ of the men and $4 \%$ of the women had it successfully controlled by drugs.

A descriptive study was conducted to find the risk factors, mortality, and complications associated with myocardial infarction in young adults of the ICCU of KMC, Manipal. Sample size was 74, selected through purposive sampling technique. Subjects were subjected to biochemical tests, ECG, etc. The study findings revealed highest incidence (64\%) of acute myocardial infarction in the age group of 36-40 years with the risk factors like hypertension, diabetes mellitus, smoking and physical inactivity which were contributing to the development of CAD.

An epidemiological study was done to examine the effect of demand-control model of job strain contributing to the determinants of CHD. The subjects were 4350 workmen aged 20-64 years and the data was collected using a questionnaire. The relationship between job strain and the health outcomes was determined by logistic regression analysis. The results revealed those in high strain job consistently reported poorer health on all measures than men with lower strain. Similarly men reporting low job strain were lest likely to report poor health in 5 out of 6 health outcomes. Those with intermediate levels of strain tended to have intermediate prevalence rates for poor health. The pattern of association between job strain and CHD was independent of coronary risk factors.

\section{Literature Review related to The Risk}

Factors On Occurrence Of Coronary Artery

\section{Disease}

A descriptive study was done to assess the knowledge and attitude regarding CVD risk and prevention in patients with coronary or peripheral arterial disease and in this study they compared the perception regarding risk of $\mathrm{CV}$ events and benefits of CVD risk factor reductions between patients with peripheral arterial disease (PAD), patients with CAD (and patients without atherosclerosis - no diseases). Three hundred and forty-eight subjects were included in the study and three groups were there, and the subjects were interviewed regarding the risk of mortality, CVD and the importance of CVD risk factors reduction for patients with PAD and CAD. The results revealed that in all groups the risk of MI, stroke and death was higher for a patient with CAD than for a patient with PAD.

A cohort follow-up study was done among 51,529 US male health professionals 


\section{SDES-International Journal of Interdisciplinary Research \\ (Peer Reviewed Refereed Journal) \\ Crossref DOI: 10.47997/SDES-IJIR/1.2.2020.29-82 \\ https://shreedadueducational.com/journal \\ ISSN (O): 2582:7162}

aged $40-75$ years. The researchers calculated the population attributable risk of low-risk lifestyle factors using Cox Proportional Hazards model to evaluate relative risk of CHD and results revealed over 16 years of follow-up, there were 2,183 cases of CHD. Men with the five low risk lifestyle factors were at decreased risk for incident CHD (0.43\%, 95\% CI, 0.09-0.19) compared with men who did not make lifestyle changes during follow-up, those who adopted $\geq 2$ additional low risk lifestyle factors had a $27 \%$ (95\% CI, 7-43\%) lower risk of CHD and the authors concluded that adherence to healthy lifestyle habits may prevent a majority of CHD events among US healthy men.

A descriptive study was done to find the detailed physical activity profiles of educated, employed urban Indians and to ascertain their knowledge about the benefits of exercise, their concept of ideal exercise, and the constraints of achieving it. About $40 \%$ subjects between the ages 25 and 58 years were studied. Women were significantly more active than men largely due to enhanced household activity; $50 \%$ of the subjects were aware of the benefits of exercise in preventing heart disease. Lack of motivation and time were the most often cited reasons for being unable to achieve ideal exercise goals.

A field experiment community study was undertaken in three northern California towns to determine whether community health education can reduce the risk of CVD and the subjects varied between 12,000 and 15,000 and in two of these towns, intensive mass education campaigns were conducted against CV risk factors over a period of two years and the third community served as control. The people from each community were interviewed and examined before the campaign began and one and two years afterwards to assess the knowledge of behaviour related to CVD and to measure the physiological indicators of risk. The results showed that in the control community the risk of CVD increased over two years, but in the intervention communities there was a substantial and sustained decrease in risk. The net difference in estimated total risk between control and intervention samples was 2328\%.Hatmi.Z.N, Tahvildan.s, Mottag.S.A.A 2007 conducted study to "asses the prevalence of coronary artery disease risk factors in Iran population". A descriptive cross sectional survey was conducted involving 3000 healthy adults at 18 years or 
above who were recruited with cluster random sampling. Result of the study was the average age was $36.23=/-5$ 15.26. There was 1381 female (46\%) and 1619 male (54\%).Out of which $6.3 \%$ were diabetes, $21.6 \%$ were smoker and $15 \%$ positive family history. $61 \%$ had total cholesterol level $>200 \mathrm{mg} / \mathrm{dl}, \quad 32 \%$ triglyceride $14 \quad>200 \mathrm{mg} / \mathrm{dl}, \quad 42.5 \%$ LDL. $130 \mathrm{mg} / \mathrm{dl} ， \quad 5.5 \%$ HDL， 35， $13.7 \%$ systolic Blood pressure.140mmof $\mathrm{Hg}, 9.1 \%$ diastolic blood pressure.90mmof $\mathrm{Hg}$ and $87 \%$ of them were physically incentives. The study concluded that clinical and para clinical data indicated that Iranian adult population are a high level of coronary artery disease risk factors.

T. Ellingsen A. Bener A.A. Gehan 2007 done a cohort study to investigate the effects of shift work on coronary heart diseases in 2562 men from different Asian races working in a fertilizer plant in the Middle East. The incidence of coronary heart disease is significantly higher in shift workers (13.5\%) compared with the daytime workers (7.1\%). Also, there was a statistically significant difference between shift workers and daytime workers concerning hypertension and cerebrovascular incidents.

\section{Literature Review related to}

\section{Effectiveness of structure teaching} programme.

A study was conducted to assess the effectiveness of PTP regarding ABG and ABG interpretation for staff nurses working in ICUs of selected hospitals in Bangalore. The findings of the study showed the differences between means of pre-test knowledge scores at 0.01 level $(\mathrm{P}<0.01)$. There was large improvement from pre-test scores (15.7) to post-test knowledge scores (20.5) and a significant improvement in post-test II knowledge scores (21.3) and there was a large improvement from pre-test interpretation scores (50.6) to post-test (103.6) a slight increases in post-test II interpretation scores (109.2). This indicates that the planned teaching programme was effective.

\section{BIBLIOGRAPHY}

01. Viswanathan Mohan, MD, PhD, Raj deepa, PhD, MPhil, Clinical study: coronary artery disease October 12, 2000; revised manuscript received March 19, 2001, accepted May 15, 2001

02. Manish bansal, Ravi R Kasliwal article.comparative accuracy of different risk scores in assessing cardiovascular 
risk in Indian available from http://www.ncbi.n/m.nih.gov/pmcl

03. Jai jagdish, N Hiramat(Rajiv Gandhi University)a study to assess the effectiveness of planed teaching programme on knowledge regarding coronary artery disease and its prevention among the primary school teacher of selected school at tankeravailable from http :// www.rguhs .ac.in/../05-n///-7540, doc Kaur J, Bains K. Report of national workshops on national rural health mission. Indian Journal of Public Health 2006 AprJun;97-9.

04. Bhattacharya M. Coronary heart disease prevention in India. The Journal of the Royal Society for the Promotion of Health 2003;123(4):222.

05. Bulwer BE. Common risk factors in chronic diseases. The western diet and negative lifestyles. Evidence based insights into protecting your health and preventing the major lifestyle killers of modern man. Social Science Medicine 2003;49(1):130-6.

06. Yuba R, Rabi M, Ramesh S. Public knowledge on heart attack in a population survey in Nepal. Indian Heart Journal 2005 Sep-Oct;57:543-54.
07. Kirkland SA, MacLean DR, Langelle DB, Joffres MR, McPherson KM, Andrew P. Knowledge and awareness of risk factor for cardiovascular diseases among Canadians 55 to 74 years of age: results from the Canadian heart health surveys. Canadian Medical Association Journal 2004 Feb;25:510-6.

08. McDermott MM, Mandapat AC, Moates A, Albay M, Chiou E, Celic L. Knowledge and attitude regarding cardiovascular disease risk and prevention in patient with coronary or peripheral arterial disease. Arch Inter Med 2003 Oct 13;163(18):2157-62.

09. Chiuve SE, McCullough ML, Sacks FM, Rimm EB. Healthy lifestyle factors in the primary prevention of coronary heart disease among men. Circulation 2006;114:160-7.

10. Vijay S, Balasangameshwara $\mathrm{W} H$, Udhya Kumar. Coronary heart disease prevention in India:a descriptive study. J R Soc Promot Health .2003 Nov; 123 (4) $: 222-8$. 